(REVIEW ARTICLE)

\title{
Impact of COVID 19 on the lifestyle of kids: Utilizing idle time
}

\author{
Kamrul Laila 1, ${ }^{*}$ and Shahana Akhter Rahman ${ }^{2}$ \\ ${ }^{1}$ Assistant Professor, Department of Paediatrics, Bangabandhu Sheikh Mujib Medical University, Dhaka, Bangladesh. \\ ${ }^{2}$ Professor, Department of Paediatrics Bangabandhu Sheikh Mujib Medical University, Dhaka, Bangladesh.
}

Publication history: Received on 03 November 2020; revised on 08 November 2020; accepted on 11 November 2020

Article DOI: https://doi.org/10.30574/wjarr.2020.8.2.0412

\begin{abstract}
Corona virus disease 2019 (COVID-19) is an infectious disease caused by a novel Corona virus. WHO had declared it as a pandemic on 11 March 2020. To halt the COVID-19 transmission almost all the countries had nationwide school closure and classes have been shifted to home-based distance-learning models using internet and electronic devices. There have been gross impairment of family life, academic and extracurricular activities and social interaction of kids. In this article, the impact of COVID 19 on children has been discussed along with few thoughts regarding utilization of this critical period in a positive way.
\end{abstract}

Keywords: COVID 19; Pandemic; Lockdown; Lifestyle; Idle time.

\section{Background}

Corona virus disease 2019 (COVID-19) is a highly infectious acute respiratory disease. The World Health Organization (WHO) was informed of cases of pneumonia of unknown microbial etiology from Wuhan City, China on 31 December 2019. The WHO later announced that a novel Coronavirus had been detected in samples taken from these patients. Since then, the epidemic has escalated and rapidly spread around the world. WHO had declared it as a public health emergency of international concern on 30 January 2020, and subsequently as a pandemic on 11 March 2020 [1].

Globally, more than 213 countries and territories of the world have reported 53,507,282 confirmed cases of COVID-19, including 1,305,164 deaths [2,3] Fewer cases of children have been reported in children (age 0-17 years) compared with adults. [4,5] Hospitalization rates in children are also significantly lower, suggesting that children may have less severe illness from COVID-19 compared to adults.[6,7] In Bangladesh, till date (10 October 2020) total number of confirmed COVID cases are 378266 with 5524 death cases [8] However, there is no accurate data regarding the number and percentage of Bangladeshi paediatric population suffering from COVID 19. Bangabandhu Sheikh Mujib Medical University (BSMMU), Dhaka, Bangladesh is running a fever clinic for the febrile patients, investigating the suspected patients by RT PCR testing for Covid-19 and also providing treatment during this pandemic. Approximately 35,000 suspected cases (including 2047 children) attended fever clinic from March to July 2019. Among the suspected paediatric population, $17.5 \%$ (359 cases) were confirmed cases for COVID 19 with an age range between 3 months to 18 years. Maximum case detection was in June 2020. Male: female ratio among the paediatric cases was 1.07:1[9]

Children infected with SARS-CoV-2 may have some non-specific symptoms like fever, fatigue, headache, myalgia, cough, nasal congestion or rhinorrhea, new loss of taste or smell, sore throat, shortness of breath or difficulty breathing, abdominal pain, diarrhea, nausea or vomiting, poor appetite or poor feeding etc. [10] Evidence suggests that as many as $45 \%$ of pediatric infections are asymptomatic.[11] Children with certain underlying medical conditions (genetic, neurologic, metabolic conditions, or with congenital heart disease, malignancy etc) and infants (age $<1$ year) might be at increased risk for severe illness from SARS-CoV-2 infection. Multisystem inflammatory syndrome in children (MIS-

${ }^{*}$ Corresponding author: Dr. Kamrul Laila

Assistant Professor, Department of Paediatrics, Bangabandhu Sheikh Mujib Medical University, Dhaka,Bangladesh.

Copyright $(2020$ Author(s) retain the copyright of this article. This article is published under the terms of the Creative Commons Attribution Liscense 4.0. 
C) is a serious condition that appears to be linked to COVID-19. In children with MIS-C, some organs and tissues including heart, lungs, blood vessels, kidneys, digestive system, brain, skin or eyes become severely inflamed. Signs and symptoms depend on the affected organs of the body [12].

Schooling is very important for achieving academic skills, interpersonal communication and psychological counseling. Evidence shows that whenever children are beyond schooling (e.g. weekends and long vacations), they become physically less active, have prolonged screen time, irregular sleep schedules and less healthy diets, resulting in excessive weight gain [13]. To halt the COVID-19 transmission, almost all the countries of the world have nationwide school closure and classes have been shifted to home-based distance-learning models using internet and electronic devices. As a result, children are feeling isolated, anxious, bored and uncertain as there are physical distancing and quarantines for indefinite period of time. Some children are more concerned and grieved over the impact of the disease on their families. All of these may adversely impact children's physical and mental health.

To prevent the outbreak of COVID-19, the Government of The Peoples' Republic of Bangladesh has also closed the academic institutions since March 2020. Therefore, about 3.7 millions of students and a million of teachers are staying atPaediatric population of Bangladesh

Bangladesh is the eighth-most populated country in the world with almost $2.2 \%$ of the world's population. According to the 2019 revision of the World Population Prospects, the population stood at 161,376,708 in 2016 .Among them, around 40 percent are children. [15]

\section{Lifestyle of Bangladeshi children}

In Bangladesh, most of the households consist of parents and their children. However; there are joint families also. Children are generally not given important responsibilities beyond their own academic works. Students are not employed and are totally dependent on their parents. But unfortunately children from lower socioeconomic class at times remain engaged in family earning processes and deprived from an usual childhood full of academic activities and childhood development.

Schools and other similar academic institutions provide the major part of formal education and occupy a significant period of daily life. Schools train the children to know about different cultures, beliefs and thoughts by interaction with different people. Students join clubs and other extracurricular activities through schools. So, most of the Bangladeshi children start their day rushing to the academic institutions, and spend a busy day there till the evening involving in curricular and extra-curricular activities. After that, a rural child has the opportunity to have an outdoor games or events. It is a common custom in Bangladesh, that children must get in home before the Magrib prayer (evening prayer) legislated by parents and this heritage is practiced for years.The scenario is a bit different in urban area. The families are nuclear with few sibs and there is scarcity of outdoor activities. Most of the urban children are gadget or television dependent during their leisure time. There is provision of getting personal tuition from house tutors or tuition centers in the evening making the schedule busier. Some parents do try to arrange facilities for their child's extracurricular activities. The day ends with a preparation for next day class and the cycle repeats. However, children remain a bit relaxed during weekends.

\section{Impact of COVID 19 on daily life of a student}

During this Corona pandemic, there has been a huge loss in lives, jobs, education and the economy of the Country. Being a new viral disease, vaccines are not yet available. So, taking extensive precautions such as maintaining hygiene protocol (e.g. regular hand washing, avoidance of face to face interaction etc.), social distancing and wearing of masks are of great importance. Social gathering is strictly prohibited to prevent the spread. Many countries are locking down their population and enforcing strict quarantine to control the havoc. There have been closure of educational institutions and postponement of examination, closure of recreation centres (e.g. restaurants, religious places, movie and play areas), undue stress among the population, disruption of cultural, religious and festive events, cancellation of sports and tournaments and national and international travelling.

School closures have impacts not only on students, but also on teachers and families with some economic and social consequences including logistics for digital learning and interrupted learning. School provides a structured routine to the students. The routine of getting up in the early morning, going to schools and coming home at a scheduled time provides a sense of regularity in their lives. The predictability of knowing that third period math class follows second period history class allows students' brains to focus on academic content. After school closure, students have lost these 
structures. For a certain period of time this greater amount of freedom might be enjoyable. But after that, it is likely to fall behind, to be distracted by other more desirable options (Netflix, video games, social media), or to become depressed.

School is not only about academics, it is also about social interactions. Many friendships are initiated by sitting next to each other in class. Groups of friends enjoy leisure time together every day. Through their interactions with teachers and other school personnel young people learn to interact with non-family members and are exposed to a variety of different cultures, perspectives and ways of living that may be different than their own. [16]

Like many other countries in the world, Bangladesh has also adopted online learning and many schools are conducting online classes. There are, however, no specific and well-designed guidelines to conduct the online classes. Thus, different schools and educational institutions are conducting online classes and tests according to their ability. A large number of school teachers in the country are also facing some difficulties to conduct online classes. Some of them don't have appropriate devices and logistics. Many of them have to depend on cell phone data connection which is expensive. Those who have broadband Wi-Fi service also sometimes face disruptions. Many students cannot attend their classes due to lack of logistics.

Moreover, students are not getting the face to face contact, interactive sessions and practicing opportunities in the Zoom-based classroom. Though off-line practice or home task is given, evaluation becomes difficult. A large number of guardians have limitations of understanding and thereby fail to cooperate. Without the assistance of the guardians, primary level students cannot following online classes. A good number of teachers and students, especially from villages and semi-urban areas, are yet to be equipped with the changed patterns and practices of teaching. [17] in addition, there are some health hazards e.g. online classes may affect the eyesight due to long hours of exposure. Young children including playschool and primary grades students usually have low concentration power, and cannot sit for a longer time without face to face contact and interactive session. Extracurricular activities are also affected. Many students used to enjoy participating in sports, music, school plays and a variety of other activities. Participating these activities are important for development of self-confidence and self-identity. [16]

\section{Psycho-social Impact on Children}

Home confinement imposes immediate and long term psychosocial impact on children due to sudden drastic change in their lifestyle. Mental development depends not only on nutritional and medical care, but also on proper parental companionship. [18] Reports of child abuse, neglect, exploitation and domestic violence are increasing alarmingly at the time of COVID-19 pandemic and lockdown. Parental anxieties over health, finance, partial inactivity, frustration encircling forced home-stay are factors behind this rapid soaring of domestic violence. [19] Both direct and passive exposure to abuse, psychological aggression and physical punishment may result in impaired neuropsychiatric development, higher rates of psychosomatic and neuro-psychiatric disorders, substance abuse and even suicidal thoughts. Moreover, children from poor communities, who frequently suffer from asthma, poor nutrition and other infectious diseases totally depend on schools for primary healthcare, are deprived at this period. [20]

COVID-19 has opened up different avenues for more cybercrimes. Criminals are often taking the advantages of relaxation of cyber-security at this hour. As because, children are expected to be more vulnerable, less supervised and more online exposed, child abuse materials are also promoted organizedly by the cyber criminals and children are becoming easy targets for them. Strict parental vigilance along with monitoring from cyber cells are mandatory to prevent this psycho sexual aberrancy. [21]

While periods of lockdown is a golden opportunity for parents to interact with their kids, the story is different for the kids of the frontline COVID fighters including health care professionals, law and security forces. Fear and guilt of contamination overwhelms them. Breastfeeding is being jeopardized in the frontline healthcare worker mothers. These children are missing their parents more than ever due to protracted periods of distancing. At the same time, they are probably feeling proud for their heroic parents at some corner of their hearts. The wound of observing humiliation of their parents by evicting them from rented house may create long term psychological consequences like anger, aggression and generalized disregard for the society. [22]

\section{How to utilize this idle time}

The saying "Every dark cloud has a silver lining" is very true even in the ongoing COVID 19 situation. This pandemic has changed the way we live and the things we do on a daily basis. It has taught us to realize the importance of togetherness. 
We are lucky that we are still being able to wake up, see the sunrise, feel the air and to breathe in the wonderful air around.

Students can use their quality time in studying and getting involved in other activities where they have interest. They can try practicing all they have learnt from the online classes. Some schools, however, do not have online classes. And also there are a lots of students who are struggling financially and do not have the facilities to attend online classes. The educational institutions should build up a fund to help these students during this difficult time so that students are able to complete their original syllabus, study by themselves and take help from their elders. Parents can also help their young children to get engaged properly in their studies.

Schools teach students to be more disciplined and to follow a set of rules. What parents can do, they can make an easy schedule to be followed. It should include regular study time, exercise and creativity (music/dance/art). Students should also grow a habit of reading books in their leisure time. This is essential for the younger students as these practices will help them as they grow older and it will also make the lockdown less mundane to them [23]

During the idle time books or novels can be read. Reading has many advantages. Reading increase knowledge and vocabulary. There are other benefits of books and novels like stress reduction, improvement in writing skills, mental stimulation and ethical aspects of life. Acquiring new knowledge never loses its value. Idle time of the current situation provides enormous time to sink in the ocean of books to enrich the knowledge and spiritual development. Technology has made it quite simple to learn a new language also with CDs, downloads, and podcasts to become bilingual (or multilingual). Knowledge of other languages can make one more presentable [24]

Religious education is of utmost importance. It provides an individual with insight into different religious practices, faiths, beliefs and helps people to know and familiarize with different cultures around the world. It builds tolerance among people with different background and religious beliefs. Overall, it serves to build a better society, community, and culture of the human being. So, one can enrich the religious knowledge by reading related books. Biography of religious leaders and great persons including philosophers, scientists, great leaders, philanthropists, reformers and other influential persons can be read so that individuals become familiar about their identity and struggle and learn to respect them and try to learn values and ethics. This is a time where our children can learn about the great liberation war through reading related books, storytelling about liberation wars etc. Though that, they can learn about our glorious history and our great leaders including freedom fighters.

Setting a clear goal is very important to become successful in life. People who write down their goals are far more likely to achieve them than those who simply think about a goal, or those who have no goal at all. If the spare time is used to record the daily and long-term goals, it would eliminate other distractions and gives an objective to focus on. Hence, time that would otherwise be spent on mindless diversions will be converted into productive time. [24]

Although it is not possible to spend time with friends and relatives now a days, one can have a better bonding using telephone, or virtual technologies. This is the time to re-establish the connection with long lost friends and family members that once were a dear part of life. There is nothing more precious and rewarding than a healthy and fit body. Now this extra time can be utilized by working on fitness regime. Being healthy does not only mean physical fitness, but it also includes maintaining peace of mind which could be achieved by meditation and yoga. Meditation helps to reduce stress, increase energy, enhance the immune system, and benefit in a lot more ways. For younger children, parents can encourage some indoor games such as hide and seek, skipping, riding a tricycle inside home, jumping, dancing etc. In idle time one can play Ludu, Carrom, Sudoku, Uno, Chess or other puzzle games which may increase thinking power.

Gardening gives us a sense of stress relief. Children can get involved in gardening if there is scope. Planting new seeds, controlling weeds, watering plants adding adding some garden arts, are a few gardening activities for being engaged in. Pets are very relaxing, time can be spent with them if there are pets in home. Creative activities like painting,drawing, photography, doodling, quilling, paper cutting, writing poems \& songs, etc. can be nurtured for the peace of mind as well as do complete justice to free time. New fashion looks can be created by sorting out, mixing and matching the clothes and accessories already possessed. By doing so, a new look \& style can be created as well as the wardrobe can be utilized in an effective manner.

Watching Television is a good way to know the present affairs. Cartoons, sports, movies or songs can be enjoyed for entertainment. In today's world, internet has become a need to everyone. It is very beneficial for us if used in a right way. In free time, favorite topics or topic of interest can be learnt in one click. Parental monitoring is very important while children are online for safety reasons. Parents may limit what sites a child visits online, or how much time the child spends on the internet. 
True happiness comes from serving others. So instead of watching TV for a long time, it would be better to help others in the family. Older children can help the younger ones for academic and extra academic activities. Kids can help parents making and serving meals, and other household activities. These activities are not overly demanding of time and may provide a feeling of happiness.

The International Federation of the Red Cross and Red Crescent Societies (IFRC), UNICEF and the World Health Organization (WHO) issued new guidance to help protecting children and schools from transmission of the COVID-19 virus. In the event of school closures, the guidance includes recommendations to mitigate against the possible negative impacts on children's learning and wellbeing, including remote learning options such as online education strategies and radio broadcasts of academic content, and access to essential services for all children. [25] Moreover, 5 ways of keeping children safe online was also emphasized. According to them, having an honest dialogue with children about whom, how, when and why they would communicate with is the first precaution. Others are, helping them learn to keep personal information private, especially from strangers, spending time with them to identify age appropriate apps, games and other online entertainment, encouraging the children to be kind and respectful to classmates, to be mindful of what clothes they wear and to avoid joining video calls from a bedroom and lastly balance online recreation with offline activities, including time outside, if possible. UNICEF specialists, international cyber bullying and child protection experts, and Facebook, Instagram and Twitter team were brought together to give their advice on ways to deal with online bullying, and these are stated nicely in the guideline.[26,27] home [14].

\section{Conclusion}

This is a time that could challenge children in different ways in terms of social disconnect, limited entertainment, and domestic problems leading to depression, loneliness or even mental disorders. But there is a lot of ways to utilize the idle time. It is a difficult time, but we have to think positive and encourage our children to stay positive. Mental peace and wellbeing are very important to be maintained and looked after. So, it is wise to pick up the activities of interest, and utilize this critical situation with some rewarding activities and beautiful memories.

\section{Compliance with ethical standards}

\section{Acknowledgments}

We acknowledge all patients suffering from COVID 19

\section{Disclosure of conflict of interest}

None

\section{References}

[1] https://bestpractice.bmj.com/topics/enus/3000168/pdf/3000168/Coronavirus\%20disease\%202019\%20\%28COVID-19\%29.pdf

[2] WHO Coronavirus Disease (COVID-19) Dashboard Data last updated: 15/11/2020

[3] Stokes EK, Zambrano LD, Anderson KN, et al. Coronavirus Disease 2019 Case Surveillance - United States, January 22-May 30, 2020. MMWR Morb Mortal Wkly Rep 2020; 69:759-765. DOI: http://dx.doi.org/10.15585/mmwr.mm6924e2external icon.

[4] Xue Li, Wei Xu, Marshall Dozier, Yazhou He, Amir Kirolos, Evropi Theodoratou. The role of children in transmission of SARS-CoV-2: A rapid review,on behalf of UNCOVERJ Glob Health. 2020 Jun; 10(1): 011101. Published online 2020 Jun 29. doi: 10.7189/jogh.10.011101 PMCID: PMC7323934

[5] Wu Z, McGoogan JM. Characteristics of and Important Lessons From the Coronavirus Disease 2019 (COVID-19) Outbreak in China: Summary of a Report of 72314 Cases From the Chinese Center for Disease Control and Prevention. JAMA 2020; 323(13):1239-1242. doi:10.1001/jama.2020.2648

[6] Kim L, Whitaker M, O'Halloran A, et al. Hospitalization Rates and Characteristics of Children Aged <18 Years Hospitalized with Laboratory-Confirmed COVID-19 - COVID-NET, 14 States, March 1-July 25, 2020. MMWR.

[7] CDC COVID-19 Response Team. Coronavirus Disease 2019 in Children - United States, February 12-April 2, 2020. MMWR Morbidity and Mortality Weekly Report. ePub: 6 April 2020. 
[8] Mannheim J, Gretsch S, Layden JE, Fricchione MJ. Characteristics of Hospitalized Pediatric COVID-19 Cases Chicago, Illinois, March - April 2020 [published online ahead of print, 2020 Jun 1]. J Pediatric Infect Dis Soc. 2020 Nov 10; 9(5):519-522. doi: 10.1093/jpids/piaa070.

[9] Poline et al. Systematic SARS-CoV-2 screening at hospital admission in children: A French prospective multicenter study. Clinical Infectious Disease. ciaa1044, https://doi.org/10.1093/cid/ciaa1044

[10] Shekerdemian LS, Mahmood NR, Wolfe KK, et al. Characteristics and Outcomes of Children With Coronavirus Disease 2019 (COVID-19) Infection Admitted to US and Canadian Pediatric Intensive Care Units. JAMA Pediatr. 2020 May 11 [Epub ahead of print]. Available from: https://doi.org/10.1001/jamapediatrics.2020.1948

[11] Wang G, Zhang Y, Zhao J, Zhang J, Jiang F. Mitigate the effects of homeconfinement on children during the COVID19 outbreak. Lancet;395(10228): 945-947.

[12] Ahmed M. Managing schools, learning and student wellbeing during Covid-19. The Daily. 2020.

[13] Overall total population - World Population Prospects: The 2019 Revision" . population.un.org (custom data acquired via website population.un.org (custom data acquired via website). United Nations Department of Economic and Social Affairs, Population Division. Retrieved 9 November 2019.

[14] Tanim Asjad, Teachers yet to be at ease with online class, The Financial Express, September 03, 2020.

[15] Wang G, Zhang Y, Zhao J, Zhang J, Jiang F. Mitigate the effects of home confinement on children during the COᄀVID19 outbreak. Lancet. 2020;395:945-7.

[16] UNICEF. COVID-19: Children at heightened risk of abuse, neglect, exploitation and violence amidst intensify 7 ing containment measures2020.

[17] Iram Rizvi SF, Najam N. Parental Psychological Abuse toward children and Mental Health Problems in adolescence. Pak J Med Sci. 2014;30:256-60.

[18] The Hindu. Closure of schools due to COVID-19 may lead to online child sexual abuse, warns IJM.2020.

[19] Ghosh et al. Impact of COVID 19 on Children, Minerva Pediatrica. June 2020;72(3):226-35.

[20] Hridita Raihan. A Students thoughts in COVID 19 crisis in Bangladesh. 3 September 2020.

[21] COVID-19: IFRC, UNICEF and WHO issue global guidance to protect children and support safe school operations, Guidance includes practical actions and checklists for administrators, teachers, parents and children. March 2020.

[22] How to keep your child safe online while stuck at home during the COVID-19 outbreak. 5 ways to help keep your child's online experiences positive and safe Cyberb ullying: What is it and how to stop it.10 things teens want to know about cyber bullying. https://www.unicef.org/end-violence/how-to-stop-cyberbullying. 